\title{
Beneficial response of cervical dystonia spasmodic torticollis to cidofovir, an acyclic phosphonate analog (s- I-3-hydroxy-2- phosphonylmethoxypropyl) of cytosine
}

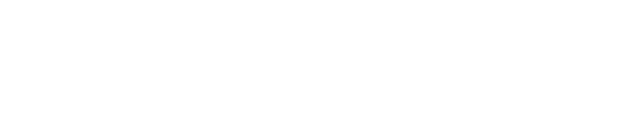

\author{
A Martin Lerner' \\ Safedin Beqaj ${ }^{2}$ \\ 'Oakland University William \\ Beaumont School of Medicine, \\ Royal Oak, MI, USA; ${ }^{2}$ Pathology Inc., \\ Torrance, CA, USA
}

\begin{abstract}
We report the case of a 23-year-old healthy man who had sudden onset of cervical dystonia spasmodic torticollis in October 2012. He was treated with intravenous cidofovir, which was started on February 20, 2013, followed by oral valganciclovir and famciclovir. Pulling of the neck and tilt of the head far to the left is no longer present (as at April 22, 2014). Human herpesvirus 6 total antibody titers fell from 11.27 (negative $<1$ ) on January 15, 2013 to 1.89 on August 5, 2013. To our knowledge, this is the first case of improvement in cervical dystonia spasmodic torticollis with treatment.
\end{abstract}

Keywords: cidofovir, spasmodic torticollis, cervical dystonia

\section{Introduction}

Cervical dystonia spasmodic torticollis is a chronic, painful, disfiguring condition of unknown cause. Symptomatic therapy has limited value in this illness. We report the case of a young man whose repetitive cramping and pulling of the neck to a horizontal position was responsive to intravenous cidofovir (S-1-3-hydroxy-2 phosphonylmethoxypropyl cytosine) followed by oral valganciclovir (L-valyl ester of 9-1, 3-dihydroxy-2-propylmethyl guanine) and famciclovir (the diethyl ester of (9-4hydroxy-3-hydroxy-3-hydroxymethylbut-1-y1) guanine).

\section{Case report}

In October 2012, a 23-year-old public accountant who had recently recovered from pertussis developed painful pulling of his neck and head, with a tilt far to the left. The abnormal neck posturing continued. The fourth and fifth fingers of his left hand were numb, coincident with his pathological neck movements, but this symptom had resolved by the time of his first visit to the clinic on January 15, 2013. His thyroid gland was asymmetrically enlarged without nodules. Except for his neck, the neurological examination was negative. With the onset of the neck dystonia, there had been a diffuse papular rash, but this too was now absent. His painful head tilt continued.

No similar illness had occurred in the patient's family. Magnetic resonance imaging of the brain and cervical spine were negative. Complete blood count, aspartate aminotransferase, alanine aminotransferase, creatinine, urinalysis, triiodothyronine $\left(\mathrm{T}_{3}\right)$, thyroxine $\left(\mathrm{T}_{4}\right)$, and thyroid-stimulating hormone levels were normal. Epstein-Barr virus (EBV) serum capsid antigen immunoglobulin (Ig) $\mathrm{M}$ was $<20$
Correspondence: A. Martin Lerner, MD, PC 32804 Pierce St, Beverly Hills, MI 48025, USA

$\mathrm{Tel}+\mathrm{I} 2485409866$

Fax + I 2485400139

Email amartinlerner@yahoo.com 
(negative). EBV early antigen diffuse was $<20$ (negative) and EBV early antigen restrictive was 20 (negative, $<20$ ). Cytomegalovirus (CMV) serum IgM was $\leq 20$ (negative). CMV IgG titer was 235 (negative, $\leq 20$ ). Human herpesvirus 6 (HHV6) IgM was $<1$ (negative), but total serum HHV6 antibody titers were repeatedly positive at: 11.27 (negative, <1) on January 15, 2013, 1.89 on August 5, 2013, 4.63 on January 13, 2014, and 5.15 on March 19, 2014 (Table 1).

Valganciclovir $900 \mathrm{mg}$ orally every 12 hours was started, but the patient's aspartate aminotransferase and alanine aminotransferase levels rose in the second week, signaling valganciclovir hepatotoxicity. Cidofovir $5 \mathrm{mg} / \mathrm{kg} 400 \mathrm{mg}$ intravenously every 2 weeks was then started on February 20, 2013. ${ }^{1,2}$ Unlike valganciclovir, cidofovir is not hepatotoxic, and was continued intravenously for 26 weeks. Thus, 13 individual intravenous infusions of cidofovir $400 \mathrm{mg}$ were given. At the conclusion of these infusions, famciclovir 1,500 mg every 6 hours was continued orally. The patient's head tilt and pain disappeared after completion of his course of cidofovir, but recurred, with a less severe head tilt, 2 months later. Valganciclovir was started again but now orally at $450 \mathrm{mg}$ in the morning, every 48 hours to an attempt to avoid hepatotoxicity. Famciclovir 1,500 mg orally every 6 hours was continued. By March 19, 2014, the patient's head tilt was again no longer visible.

The intravenous cidofovir dosage of $5 \mathrm{mg} / \mathrm{kg}$ was based on this patient's ideal weight of $80 \mathrm{~kg}$. If he had been overweight, cidofovir would have been dosed at $2.5 \mathrm{mg} / \mathrm{kg}$ for the excess weight over ideal. This was our judgment based upon

Table I HHV6, CMV, and EBV serum ELISA antibody titers* in a 23-year-old male with idiopathic cervical dystonia spasmodic torticollis

\begin{tabular}{|c|c|c|c|}
\hline Date & HHV6 & CMV & EBV \\
\hline \multicolumn{4}{|c|}{ Serum antibody titers } \\
\hline \multirow[t]{2}{*}{ January 15,2013} & $1 \mathrm{I} .27(\leq \mathrm{I})$ & $235(\leq 20)$ & $\mathrm{EA}(\mathrm{R}) 20(\leq 20)$ \\
\hline & & & EA (D) neg $(\leq 20)$ \\
\hline \multirow[t]{2}{*}{ April II, 2013} & 3.37 & - & EA (R) 20 \\
\hline & & & EA (D) 20 \\
\hline \multirow[t]{2}{*}{ July 8,2013} & 3.73 & 232 & $E A(R)$ neg \\
\hline & & & EA (D) 20 \\
\hline August 5,2013 & 1.89 & 235 & - \\
\hline \multirow[t]{2}{*}{ January 30,2014} & 4.63 & - & $\mathrm{EA}(\mathrm{R}) 20$ \\
\hline & & & EA (D) neg \\
\hline \multirow[t]{2}{*}{ March 19, 2014} & 5.15 & - & $E A(R) 20$ \\
\hline & & & EA (D) 20 \\
\hline
\end{tabular}

Notes: *Serum antibody titers are total antibody. Repetitive ELISA serum IgM HHV6, CMV and EBV titers were negative. Laboratory studies were done by LabCorp Dublin, OH, USA.

Abbreviations: HHV6, Human herpesvirus 6; CMV, Cytomegalovirus; EBV, EpsteinBarr virus; ELISA, enzyme-linked immunosorbent assay; EA, early antigen; D, diffuse; $R$, restricted; neg, negative. similar practices to prevent toxicity. Cidofovir was administered in the short-stay unit at William Beaumont Hospital, Royal Oak, MI, USA. Intravenous cidofovir $400 \mathrm{mg}$ in $1 \mathrm{~L}$ of normal saline was preceded by administration of probenecid, a lipid-soluble benzoic acid derivative, at $2 \mathrm{~g}$ orally 3 hours earlier. Probenecid inhibits renal tubular secretion of cidofovir, thus sparing the renal tubules from excessive and possibly toxic renal tubular concentrations. A second $1,000 \mathrm{~mL}$ intravenous normal saline infusion followed the initial infusion. Probenecid $1 \mathrm{~g}$ orally was repeated 2 hours after completion of the cidofovir infusion. Finally, a third dose of probenecid $1 \mathrm{~g}$ was given orally 8 hours later. ${ }^{3-8}$ Thus, three oral doses of probenecid were given at each cidofovir infusion (ie, $2 \mathrm{~g}$ 3 hours before, $1 \mathrm{~g} 2$ hours after, and $1 \mathrm{~g} 2$ hours later).

Physician visits on the day after each cidofovir infusion confirmed continuing normal renal function (creatinine $<1.5 \mathrm{mg} / \mathrm{dL}$ and creatinine clearance $>59 \mathrm{~mL} / \mathrm{min} / 1.73 \mathrm{~m}^{2}$ ). Complete blood count, aspartate aminotransferase, alanine aminotransferase, urinalysis, sodium, and potassium were assessed at return visits every 2 weeks. All laboratory tests remained normal throughout the patient's subsequent care. Eye pain was specifically questioned for at each post-cidofovir visit. ${ }^{2}$ In total, the patient received 5,600 $\mathrm{mg}$ of cidofovir, given as 13 doses comprising $\times 5 \mathrm{mg} / \mathrm{kg}$ per infusion $(65.9 \mathrm{mg} / \mathrm{kg})$. Ondansetron $8 \mathrm{mg}$ orally three times daily was given the day before, the day of, and the day after each cidofovir infusion to prevent probenecid-induced nausea.

If renal dysfunction or eye pain had occurred, cidofovir would have been stopped. ${ }^{1,2}$ Oral famciclovir $1.5 \mathrm{~g}$ four times a day was continued along with valganciclovir $900 \mathrm{mg}$ orally once every 48 hours to an attempt to prevent relapse of torticollis. Valaciclovir and famciclovir have a similar antiviral spectrum of action. ${ }^{3-10}$ Valaciclovir inhibits reactivation of CMV in organ transplant patients. ${ }^{3}$ Famciclovir was continued rather than valaciclovir because valaciclovir is excreted by the kidney and has potential renal toxicity. ${ }^{3}$ HHV6 serum antibody titers fell from 11.27 on January 15, 2013 to 1.89 on August 5, 2013 during the cidofovir infusions (Table 1). To our knowledge, this is the first response of cervical dystonia spasmodic torticollis to therapy.

Cidofovir was stopped on October 1, 2013 and famciclovir was continued. However, at a visit on December 30, 2013, mild neck pulling to the left had reappeared. The combination of daily oral famciclovir (1,500 mg every 6 hours) and oral valganciclovir (900 mg every 48 hours) again facilitated a marked improvement in neck posturing. The patient continues to receive these antiviral agents, and his neck tilt is absent. The required duration of oral suppressive famciclovir/ 
valganciclovir combination therapy is presently unknown, as is its safety and toxicity profile. If this long-term combination therapy is continued in the future, we shall continue to monitor hematologic, hepatic, and renal laboratory studies at each monthly visit to this clinic.

\section{Discussion}

Neurological disease, meningitis, glial tumors, GuillainBarré syndrome, and encephalitis are all associated with HHV6 infection. ${ }^{11-15}$ HHV6 enters the central nervous system through the olfactory pathway and replicates in neural cells, but the primary targets of HHV6 replication are CD4+ and T-cells, B-cells, monocytes, macrophages, and epithelial cells. ${ }^{4-7}$

This case report is not a proof of cause, but the repeated consistent falls in HHV6 serum antibody titer and the apparent clinical response to cidofovir are striking (Table 1, showing HHV6 of: 11.27 on January 15, 2013; 3.37 on April 11, 2013; 3.73 on July 8, 2013; and 1.89 on August 5, 2013). There was no HHV6 IgM serum antibody.

Cidofovir is an acyclic phosphonate nucleotide analog of deoxycytidine monophosphate. Thymidine kinase is not necessary for cellular entry of cidofovir. Viral thymidine kinase selectively phosphorylates ganciclovir and acyclovir, which is necessary for the antiviral effects of these nucleosides. EBV, CMV, and HHV6 virally encoded thymidine kinase allows phosphorylation of acyclovir, ganciclovir, and famciclovir, so these antiviral nucleosides do not enter noninfected cells. Cidofovir enters cells as the monophosphate by endocytosis, thus entering both infected and noninfected cells. Cidofovir is up to ten times more potent against herpesviruses than the oral antiviral nucleosides, acyclovir, famciclovir, ganciclovir (ie, the $\mathrm{ID}_{50}$ is markedly greater for these nucleosides). ${ }^{4}$ Cidofovir is a natural monophosphate nucleotide. After nonspecific intracellular absorption by cytolysis, cidofovir is metabolized by cellular phosphatases to its active moiety, the diphosphate. The diphosphate moiety inhibits herpesvirus DNA polymerase at a 1,000-fold lower concentration than that required for inhibition of cellular DNA synthesis. Cidofovir can be incorporated either terminally to prevent chain elongation or internally to allow DNA chain growth. The intracellular half-life of cidofovir is 17-30 hours, allowing the infrequent administration that we chose. ${ }^{16}$ Intracellular binding of cidofovir to choline may account for the prolonged half-life.

Cidofovir is nephrotoxic to renal proximal tubular cells. Slow administration of cidofovir, maintaining intravenous hydration, and simultaneous administration of probenecid, which competitively inhibits access of cidofovir to renal tubular cells, is critical for safe use of cidofovir.

If glomerular filtration had decreased, proteinuria had appeared, or eye pain (iritis, intraocular hypotonia, cataracts) ensued, the infusions of cidofovir would have been stopped..$^{1,2}$ Other potentially nephrotoxic agents, ie, aminoglycosides or nonsteroidal anti-inflammatory agents, should be avoided during treatment with cidofovir. ${ }^{8,11-14}$ Cidofovir and probenecid share small sulfur moieties and may cause sulfur toxicity. Preliminary testing with initial small doses of cidofovir are indicated if sulfonamide sensitivity is suspected.

Spasmodic torticollis is a chronic and severely disabling condition. We suggest cautious use of cidofovir as early as possible after onset of the disease. Our fortuitous early use of cidofovir in this patient may have facilitated the positive outcome. Cidofovir may be considered for a trial of treatment in other early cases of cervical dystonia spasmodic torticollis.

Cidofovir was approved for treatment of CMV retinitis in patients with acquired immune deficiency syndrome in 1996. ${ }^{17}$ Further, cidofovir enters both herpesvirus-infected and noninfected cells, unlike valganciclovir, valaciclovir, and famciclovir, which only enter infected cells. Cidofovir rapidly inhibits further spread of infection. With normal renal function, avoidance of other nephrotoxic medications, and probenecid to competitively protect the proximal renal tubules, cidofovir caused no toxicity. ${ }^{3,15,16}$ We recommend physician visits with glomerular function studies every 14 days. Cidofovir may offer a distinct advantage over antiviral nucleosides.

The response in our patient with severe cervical dystonia spasmodic torticollis may be the first hopeful report of treatment in this disease. Cidofovir acts by inhibiting herpesvirus DNA polymerases at concentrations that do not inhibit cellular DNA polymerase. The propensity of HHV6 to infect neural cells and falling HHV6 enzyme-linked immunosorbent assay serum antibody titers suggest that a prime causative candidate for cervical dystonia spasmodic torticollis may be HHV6.

\section{Disclosure}

The authors report no conflicts of interest in this work.

\section{References}

1. Nightingale SL. Cidofovir. From the Food and Drug Administration. JAMA. 1996;276(21):1710.

2. Friedberg DN. Hypotony and visual loss with intravenous cidofovir treatment of cytomegalovirus retinitis. Arch Ophthalmol. 1997;115(6): 801-802.

3. Aoki F, Hayden FG, Dolin R. Antiviral drugs (other than antiretrovirals). In: Mandell GL, Bennett JE, Dolin R, editors. Mandell, Douglas, and Bennett's Principles and Practice of Infectious Diseases. 7th ed Philadelphia, PA, USA: Churchill Livingston Elsevier; 2010. 
4. Ahmed A. Antiviral treatment of cytomegalovirus infection. Infect Disord Drug Targets. 2011;11(5):475-503.

5. De Clercq E, Holy A. Acyclic nucleoside phosphonates: a key class of antiviral drugs. Nat Rev Drug Discov. 2005;4(11):928-940.

6. Kendle JB, Fan-Havard P. Cidofovir in the treatment of cytomegaloviral disease. Ann Pharmacother. 1998;32(11):1181-1192.

7. Neyts J, Snoeck R, Balzarini J, De Clercq E. Particular characteristics of the anti-human cytomegalovirus activity of (S)-1-(3-hydroxy-2phosphonylmethoxypropyl)cytosine (HPMPC) in vitro. Antivir Res. 1991;16(1):41-52.

8. Cherrington JM, Miner R, Hitchcock MJ, Lalezari JP, Drew WL. Susceptibility of human cytomegalovirus to cidofovir is unchanged after limited in vivo exposure to various regimens of drug. J Infect Dis. 1996;173(4):987-992.

9. Craig WA. Pharmacokinetic/pharmacodynamic parameters: rationale for antibacterial dosing of mice and men. Clin Infect Dis. 1998;26(1):1-10.

10. Reymen D, Naesens L, Balzarini J, Holy A, Dvorakova H, De Clercq E. Antiviral activity of selected acyclic nucleoside analogues against human herpesvirus 6. Antivir Res. 1995;28(4):343-357.

11. Harberts E, Yao K, Wohler JE, et al. Human herpesvirus- 6 entry into the central nervous system through the olfactory pathway. Proc Natl Acad Sci U SA. 2011;108(33):13734-13739.
12. Yao K, Crawford JR, Komaroff AL, Ablashi DV, Jacobson S. Review part 2: human herpesvirus-6 in central nervous system diseases. $J$ Med Virol. 2010;82(10):1669-1678.

13. Galvan M, Rotola A, Govoni V, Granieri E, Cassai E, Di Luca D. Simultaneous Guillain-Barre syndrome and active human herpesvirus 6 infection in the central nervous system. J Clin Virol. 2007;38(3): 271-272.

14. Cohen JI. Human herpesvirus types 6 and 7. In: Mandell GL, Bennett JE, Dolin R, editors. Mandell, Douglas, and Bennett's Principles and Practice of Infectious Diseases. 7th ed. Philadelphia, PA, USA: Churchill Livingstone Elsevier; 2010.

15. De Bolle L, Naesens L, De Clercq E. Update on human herpesvirus 6 biology, clinical features, and therapy. Clin Microbiol Rev. 2005;18(1): 217-245.

16. Alrabiah FA, Sacks SL. New antiherpesvirus agents. Their targets and therapeutic potential. Drugs. 1996;52(1):17-32.

17. Lalezari JP, Drew WL, Glutzer E, et al. (S)-1-[3-hydroxy-2(phosphonylmethoxy)propyl]cytosine (cidofovir): results of a phase I/II study of a novel antiviral nucleotide analogue. J Infect Dis. 1995;171(4): 788-796.
Virus Adaptation and Treatment

\section{Publish your work in this journal}

Virus Adaptation and Treatment is an international, peer-reviewed open access journal focusing on the study of virology, viral adaptation and the development and use of antiviral drugs and vaccines to achieve improved outcomes in infection control and treatment. The journal welcomes original research, basic science, clinical \& epidemiological

\section{Dovepress}

studies, reviews \& evaluations, expert opinion and commentary, case reports and extended reports. The manuscript management system is completely online and includes a very quick and fair peer-review system, which is all easy to use. Visit http://www.dovepress.com/ testimonials.php to read real quotes from published authors. 